\title{
The Relationship between Anxietyand Achievement among Moulay Ismail University Students, Meknes
}

Akhajam Saad Eddine

Moulay Ismail University, Morocco

"Corresponding author: Akhajam Saad Eddine, Department of Psychology, Moulay Ismail University, Morocco; Tel: +46 31 764694; E-mail: akhajam.saad@gmail.com Received date: April 27, 2016; Accepted date: May 11, 2016; Published date: May 18, 2016

Copyright: () 2016 Eddine AS. This is an open-access article distributed under the terms of the Creative Commons Attribution License, which permits unrestricted use, distribution, and reproduction in any medium, provided the original author and source are credited.

\begin{abstract}
The main purpose of this study is to investigate the relationship between anxiety and scholastic achievement among students of English department at the faculty of Arts and Humanities, Meknes. This study focuses on the level of anxiety among students who belong to English department and how they can reduce anxiety inside and outside the classroom in a foreign language speaking environment without instructors' intervention. This is a quantitative research; it used two quantitative instruments that are Cattle's anxiety questionnaire and achievement test. After conducting the research using questionnaire to test the level of anxiety among the respondents and using achievement test to measure their scholastic achievement, the results revealed that girls are more anxious than boys, boys achieve higher marks in scholastic achievement, and there is no relationship between anxiety and scholastic achievement. Therefore, students have to believe that the feeling of anxiety is a fact and it is a psychological feeling. Also Teachers have to come up with various strategies to reduce anxiety among their students.
\end{abstract}

Keywords: Anxiety; Foreign language anxiety; Scholastic achievement; Foreign language classroom anxiety; Cattle's anxiety questionnaire

\section{Introduction}

Among the main developmental tasks facing children during the childhood years are the improvement of various intellectual and academic skills and the motivation to cope with them. Scholastic achievement has become an index of child's future in this competitive world. The results of education reveal the level of life, status and progress of the individual living in any place in the world and it is the main important force for the development of human life and society in general.

In every society educated people are regarded as the pillar of the future economic development which is based on scholastic achievement, therefore, everyone who gets higher marks in the academic education achieves better position in life in general. Thus, scholastic achievement occupies a very important place in education as well as in the learning process. Broadly students who get higher achievement in school, creates a self-esteem and self confidence in their inner feeling. Accordingly Redenbach [1] confirmed that students who have higher academic achievement tend to feel more confident in contrast those who lack confidence in themselves achieve less.

On the other hand, anxiety affects negatively the performance for each individual, in the sense that fear of failure and anxiety are regarded as the main factors found common in many research pertaining to the causes of destroyed academic performance.

Anxiety is a common display found in every individual especially among students. Anxiety is a kind of fear experience in response to an anticipated threat of self esteem. It is a feeling that one feels when he/she faces with real danger or threat. Moreover, everyone faces anxiety in greater or lesser degree from time to time as a result of specific situations. So anxiety reduces attention and distracts people to use their minds deliberately. The degree of anxiety varies from person to another depends on his or her personality.

\section{Literature Review}

Gardner and Macintyre [2] claimed that foreign language classroom anxiety (FLCA) is still considered to be a relatively new and developing area within foreign language research. Thus It is considered to be as a situational anxiety simply because it is limited to a specific context. Fakhri [3] said that foreign language classroom anxiety (FLCA) is related to foreign language anxiety and language-skill-specific anxiety, and fairly recently identified as distinguished from other forms of anxiety. Likewise, Horwitz et al. [4] defined FLCA as a "distinct complex of self-perceptions, beliefs, feelings, and behaviors related to classroom language learning arising from the uniqueness of the (foreign) language learning process" (p.128). Moreover, It is proved by many researchers that Horwitz et al. [4] were considered as the cofounders of FLCA. It is a standard tool for testing an individual's response to a specific stimulus of language learning. They mainly went through asking students questions about anxiety related to factors like reading, speaking, listening and writing in language class, and the effect of teacher's attitude on their performance. In Horwitz et al. [4] research about FLCA, they based on FLACA scale so as to test foreign language anxiety among university students of Texas. Pilot testing with the FLCA give an opportunity to examine the scope and severity of foreign language anxiety (P. 128) 23. The result of the study revealed that Anxious students feel a deep self-consciousness when asked to risk revealing themselves by speaking the foreign language in the presence of other people. When they questioned the respondents they found that some of them have the intention that they may skip class, over study, or seek refuge in the last rows in an effort to avoid humiliation or embarrassment of being called on to speak. Thus, FLCA is a snag for 
FLCA learners because it impedes their learning process as well as affects their scholastic achievement

Overcoming anxiety is not an easy task; still it dependents on students' psychology and their personality as well. Students suffer a lot from language or test anxiety. When students sit for an exam, they mainly feel anxious on failing or getting bad marks. That kind of feeling drives them to a psychological anxiety which is a great barrier for their success and achieving higher scores. We have seen earlier that anxiety is not a matter of easily getting rid of it, there are many factors that are internal or external that impedes students to stop anxiety. In addition to that there are many factors that influence students' performance. However, students have to reduce anxiety, to do so; there are many steps that those students have to follow so as at least to reduce it. Scientifically proved, the body and the mind are interconnected, as a result, becoming relaxed physically helps us to relax mentally, and becoming relaxed mentally helps us to relax physically. Training and preparation are the only and the best way to reduce anxiety, so training is of great importance and it helps students to take off anxiety among themselves. To be more practical here are various strategies or steps that one should follow so as to get rid of anxiety that "Teaching coping skills to children and adolescents as early as possible may help them develop effective strategies to deal with stress and minimize anxiety". Similarly, Fisak and Grills [5] proved in their research that the role modeling play is the best way to preclude anxiety or at least to manage it. Role modeling play is when a person's behavior is a success for others and it can be emulated by others mainly by young people. Educators in general and teachers in particular have to provide to their students some basic knowledge about anxiety and why not teach it to students, in the sense that they have to teach students various strategies so as to avoid the feeling of anxiety. Lindsay [6] claimed that "The classroom, in essence, can be used as a microcosm for everyday living experiences. Teachers can allow students to learn from experience and develop a positive sense of mental health (p.3)"

\section{Methodology}

This is a secondary research in nature; but it is also primary research because it deals with Moroccan students in which English is regarded as a foreign language. It is a secondary research because in the review of literature, many previous studies are conducted in the same field, bearing in mind that [7] defined primary research as research that is firsthand collection rather than found in a book, database, or journal. She also added that it is the process of collecting the data by the researcher himself or herself. On the other hand Dana [7] defined secondary research as collecting hard data that already exists about a community or communities targeted for a study. This research is quantitative, simply because the instruments that are used yield quantitative data.

The present study is an attempt to explore relationship between anxiety and scholastic achievement among university students and provide a direction for teachers and universities to help students overcome this feeling so as to achieve better in their carrier. Therefore, The knowledge generated by this study can be of help to the teachers, educationalists and students as well.

It is clear that tests and examinations at all stages of education, especially at higher education level, have been considered an important and a powerful tool for decision making in our competitive society, with people of all ages being evaluated with respect to their achievement, skills and abilities [8]. Therefore, the main interest of this research is to investigate the relationship between anxiety and scholastic achievement in addition to investigating the level of anxiety among the respondents especially between girls and boys.

Test is regarded as the main tool by which educationalists examine students' abilities and skills. But Students suffer a lot from anxiety and fear of sitting for exams. Thus, this research aims to look for the relationship between Anxiety and scholastic achievement broadly and particularly among students at the faculty of letters in Meknes.

This research is of great interest in the field of psychology and language teaching. As it is claimed in the review of literature that anxiety is experienced by every single person be it a layman or students. The study of anxiety and scholastic achievement of students at the faculty of letters assumes a very significant meaning and importance, so as to see into what extent anxiety affects or does not affect students' achievement. Therefore, it is an attempt to scout the correlation between anxiety and scholastic achievement among students at the faculty of letters with the aim of finding the level of anxiety among the respondents, study the relationship between anxiety and scholastic achievement and also the gender differences in the level of anxiety and scholastic achievement.

This research aims to answer the following main research questions that are already based on research hypotheses. a) Are males' marks different and better than females'? b) Are girls more anxious then boys? d) Does gender affect scholastic achievement? e) Is there a relationship between anxiety and achievement?

The main research hypotheses are the following: 1) Gender affects students' marks 2) There is a difference between students' marks 3) there is relationship between anxiety and scholastic achievement 4) there is a difference of the level of anxiety among girls and boys Cattel's anxiety questionnaire was used to test students' anxiety, and a final exam mark of the course of American culture was used for scholastic achievement.

This research used two types of statistics, descriptive and inferential. Descriptive statistics such as frequencies, means, and standard deviation shall be used to produce percentages of the participants (males and females and their age). Inferential statistics used for correlation and linear regression in addition to independent sample test.

The inferential statistics are used to answer the research questions and also to confirm or disconfirm the research hypotheses. More precisely they are used to test the relationship between anxiety and scholastic achievement.

\section{Results}

The significance $\mathrm{P}$ value is 0.639 ; it is greater than the typical level significance 0.05 so we accept the hypothesis which says that gender claim that gender does not affect students' marks (Table 1).

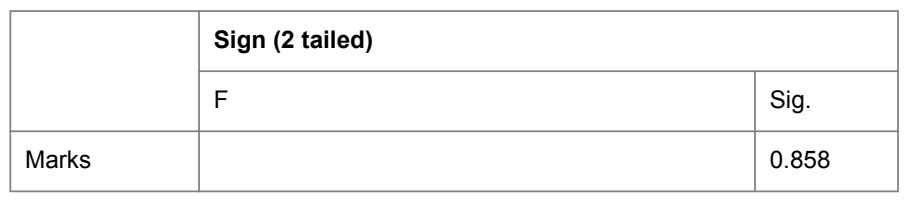

Table 1: Testing the effect of anxiety on students. 
Page 3 of 4

This table which represents group statistics shows that the mean of Male is 52.04 versus 52.55 for female. Concerning standard deviation, in male column it is 4.83 and in female column it is 5.09 . So we can say that there is a difference in Means about 0.51. Concerning the standard deviation, it is about 1 of the difference. Thus, females are more anxious than males (Table 2).

\begin{tabular}{|l|l|l|l|}
\hline Gender & N & Mean & Std. deviation \\
\hline Anxiety male & 22 & 52.04 & 4.83 \\
Female & 38 & 52.55 & 5.09 \\
\hline
\end{tabular}

Table 2: Statistic of anxiety by gender.

The result in this table shows that significance $\mathrm{P}$ value is 0.774 so it is greater than the typical level of significance 0.05 so in this case we accept the hypothesis which says that there is no affect of anxiety on student's achievement and claims that there is no effect of anxiety on students (Tables 3 and 4).

\begin{tabular}{|l|l|}
\hline & Significance $\mathbf{P}$ value (2-tailed) \\
\hline Anxiety equal variance & Sig: 0.774 \\
\hline
\end{tabular}

Table 3: Testing the effect of anxiety on students.

\begin{tabular}{|l|l|l|}
\hline & Anxiety & Marks \\
\hline Sig.(2tailed) & 60 & $\begin{array}{l}0.247 \\
60\end{array}$ \\
\hline & 60 & 60 \\
\hline
\end{tabular}

Table 4: Relationship between anxiety and scholastic achievement.

Scatter dot for showing the linear of the correlation in Figure 1.

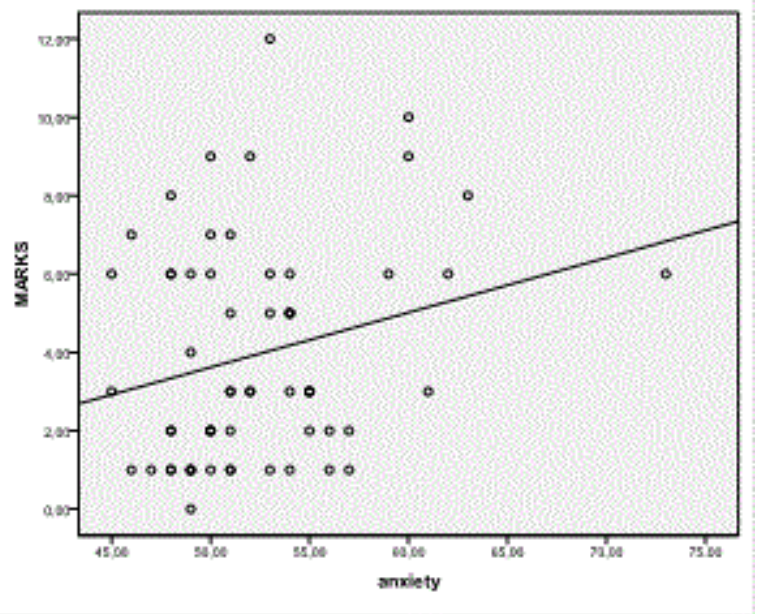

Figure 1: Linear of the correlation for anxiety and marks.

The previous Table and the graph show that the significance $P$ value is 0.058 , hence it is greater than the typical level significance 0.005 thus, we reject the hypothesis and claim that there is no relationship between the two variables. As far as Pearson correlation is concerned, it is 0.247 so there is a positive and weak correlation. Therefore, there is no correlation between anxiety and achievement among students of English department at the faculty of arts and humanities in Meknes.

\section{Conclusion}

It could be concluded that the majority of the respondents felt a degree of anxiety. More precisely, girls were more anxious than boys. As far as scholastic achievement is concerned boys got better marks than girls. So, boys seemed to achieve scholastically higher than girls. Therefore, anxiety does not affect scholastic achievement, which means that anxiety is not a factor that may affect students to achieve better in scholastic achievement, but if one feels a degree of anxiety it may or may not affect their scholastic achievement; As a result, it can become a barrier not to reach the level attained or there could be other factors like luck of preparation, luck of interest. Noteworthy is that anxiety is an external feeling that in some cases impedes students to achieve good marks or it may not. Last not least, It is found in this study that there is no relationship between anxiety and scholastic achievement.

\section{Limitation and Future Research}

Several limitations to this study must be noted. The findings of this piece of research cannot be over generalized, because of the convenient sampling which was chosen, and also due to divers feeling of each participant toward anxiety. Furthermore, there are many other external factors that may lead to suffer from anxiety and could be an open door for future research. Also, the questionnaire and the test were administered only to 60 students. Seeking opinion from just one institution is not enough. Indeed every single person from different region or institution may have different opinions about the feeling of anxiety. With time constraints I could not evaluate students in other school subjects, and that could enrich more this research and the results might give an added value; still the findings of this research are of great importance and should be taken into account.

Therefore, this research is open to other researchers to tackle other research on the same issue. I suggest tackling research on factors that may suffer from anxiety. So, it is researchable to go in this process. Moreover, it is preferable to ask teachers to provide various strategies that could help students overcome this feeling. Furthermore, it is better to deal with the relationship between anxiety and scholastic achievement in different universities. Last but not least, I suggest conducting research on the influence of anxiety on scholastic achievement in different level groups [9-12].

As a conclusion Scholastic achievement has become an index of student's future in this highly competitive world. The trend in the scholastic achievement, rate of drop outs, failures and low percentages of the students in the examinations was a question for the researcher to probe into the psychological factors that leads to poor achievement. Children who are high achievers are not necessarily more intelligent than the low achievers. Intelligence provides insight and direction to the human potential for achieving the goal.

Therefore, this research is undertaken to study the correlates of anxiety and scholastic achievement of university students with the objective to find out the relationship between anxiety and scholastic achievement, and to know the level of anxiety among the respondents as well as to bear in mind that scholastic achievement is undertaken under the factor of anxiety. 
Citation: Eddine AS (2016) The Relationship between Anxietyand Achievement among Moulay Ismail University Students, Meknes . Clin Exp Psychol 2: 126. doi:10.4172/2471-2701.1000126

Page 4 of 4

This study was conducted using two main data collection tools: Questionnaire and achievement test. The questionnaire is a form of test. It is about testing the level of anxiety among the respondents. The result of the study indicated that the majority of the respondents feel a degree of anxiety, and it was found that girls were more anxious than boys. Furthermore, anxiety and scholastic achievement were interrelated and correlated because anxiety affects scholastic achievement.

All in all anxiety in general be it language or test, should be given a lot of importance so as to help students get rid of it and achieve better position in their personal and academic life.

\section{References}

1. Redenbach S (1991) Self-Esteem, the Necessary Ingredient for Success. Esteem Seminar Programs and Publications, USA.

2. Gardner RC, MacIntyre PD (1993) A students contributions to second language learning. Part II: Affective variables LanguageTeaching.

3. Fakhri M (2012) The relationship between gender and Iranian EFL learners' foreign language classroom anxiety (FLCA). International Journal of Academic Research in Business and Social Science 2 : 147-156.
4. Horwitz EK, Horwitz MB, Cope J (1986) Foreign Language Classroom Anxiety. The Modern Language Journal 70: 125-132.

5. Fisak B, Grills-Taquechel AE (2007) Parental modeling, reinforcement, and information transfer: Risk factors in the development of child anxiety?. Clin Child Fam Psychol Rev 10: 213-231.

6. Lindsay G (2008) Positive Behavior Support: learning to prevent or manage anxiety in the school setting. University of Pittsburgh.

7. Dana D (2010) Introduction to Primary Research: Observations, Surveys, and Interviews.

8. Nadeem M, Akhtar A, Saira M, Maqboo S, Syeda UZ (2012) Impact of Anxiety on the Academic Achievement of Students Having Different Mental Abilities at University level in Bahawalpur (Southern Punjab) Pakistan. International Online Journal of educational Science 4: 519-528.

9. Coffey B (1984) State of the Art: ESP- English for Specific Purposes. The British Council Language Teaching 17: 2-16.

10. Henry H (2010) Test anxiety: how to help students overcome It. Doris Coy Educational Resource Information Center (U.S. Department of Education).

11. Malavika VV, Mokashi VG, Yada VS (2010) Relationship Between Anxiety and Scholastic Achievement. University of Agricultural Sciences.

12. Morrow K (1977) Authentic texts and ESP. 